\title{
Influence of pre-strain and carbon content on delayed cracking phenomenon in unstable austenitic steels
}

\author{
S. Berveiller ${ }^{\mathrm{a}}$, M. Kemdehoundja, E. Patoor, D. Bouscaud and M.R. Berrahmoune
}

LPMM, Arts et Métiers ParisTech, 57078 Metz Cedex 03, France

\begin{abstract}
In this paper, we study the delayed cracking phenomenon that occurs after deep drawing, at various microstructure scales. Parameters such as temperature, drawing ratio, pre-strain and chemical composition are studied. From a macroscopic point of view, the number of cracks increases with decreasing temperature or increasing drawing ratios. The higher the carbon content, the more sensitive to failure the steel is. A pre-strain favors delayaed cracking too. Martensite stress state was determined by XRD. For a given set of parameters, it is heterogeneous in a cup. Moreover it varies with drawing conditions.
\end{abstract}

\section{Introduction}

In austenitic steels, depending on the chemical composition and the thermomechanical treatment, $\gamma \leftrightarrow \alpha$ ' martensitic transformation can take place [1,2]. The characteristics of this transformation depend on many factors, such as the chemical composition of the steel, with $\mathrm{Ni}, \mathrm{Cr}, \mathrm{C}$, and $\mathrm{N}$ having a particularly strong effect on the phase transition process [3, 4]. Many other factors have a direct influence on the kinetics such as the strain, the strain level, the stress state, and the temperature. The influence of these factors has been the subject of many experimental and theoretical studies for a long time [5,6]. With the formation of martensite, a favourable additional strain which called TRansformation Induced Plasticity (TRIP) can be obtained [7]. It is required for the high formability domain. Moreover, after forming of unstable austenitic steels, a high heterogeneous residual stress state is observed.

The aim of this work is to analyze the coupling of martensitic transformation with the delayed cracking phenomenon by taking into account stress distribution in the material, focusing on the martensite phase which is the major one. The influence of a pre-strain and the chemical composition (via the carbon content) is also determined.

\section{Experimental technique}

\subsection{Material}

Experiments were performed on thin sheets of 301LN unstable austenitic steel (1 mm thickness) provided by UGINE \& ALZ. The chemical composition of the 3 grades is given table1; the hydrogen content of the 3 steels is about 3 ppm.

Table 1. Chemical composition of the alloy in wt.\% (balance iron)

\begin{tabular}{|l|l|l|l|l|l|l|}
\hline Steel & $\mathrm{C}$ & $\mathrm{Ni}$ & $\mathrm{Cr}$ & $\mathrm{Mn}$ & $\mathrm{Si}$ & $\mathrm{N}$ \\
\hline Grade 1 & 0.023 & 6.57 & 17.4 & 1.6 & 0.64 & 0.10 \\
\hline Grade 2 & 0.026 & 6.63 & 17.60 & 1.3 & 0.50 & 0.12 \\
\hline Grade 3 & 0.122 & 7.26 & 16.75 & 1.0 & 0.45 & 0.07 \\
\hline
\end{tabular}

The grade 1 has been annealed after rolling. The microstructure of the as-received steel is presented figure 1 for grade 1 . It is a single phase polycrystal (100\% austenite) with equiaxed grains of about $20-50 \mu \mathrm{m}$.

\footnotetext{
a e-mail: sophie.berveillerdensam.eu
} noncommercial medium, provided the original work is properly cited. 


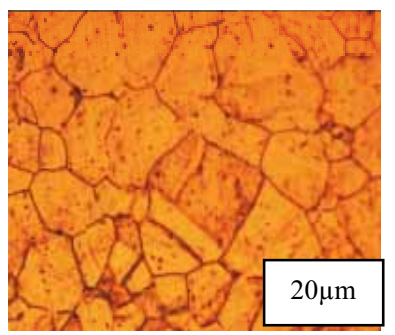

Fig. 1. Grade 1 initial microstructure observed by optical microscopy.

The grade 2 has almost the same composition but after annealing it was then cold-rolled ("skin passed"). It was used to determine the influence of a pre-strain on failure. The grade 3 differs by its chemical composition: the carbon content is 5 times bigger than the two previous ones.

\subsection{Stresses determination by X-Ray diffraction}

For this analysis, we used the classical $\sin ^{2} \psi$ method [8]. This method is based on the measurement of the interplanar spacing for various directions. Lattice strains are measured at each $\psi$-tilt of the specimen, where $\psi$ is the angle between the surface normal and the direction of the strain being measured. For isotropic materials, macroscopic diffracting planes strain values $\varepsilon_{\phi \psi}$ are linearly dependent on the $\sin ^{2} \psi$. The slope of the curve leads to the value of the stress $\sigma_{\phi}$. X ray measurements were carried out on $\{211\}$ crystallographic planes of martensite using $\mathrm{Cr}-\mathrm{K}_{\alpha}$ radiations. The measurements were done for $14 \psi$-tilt values, and the measuring time is about 30 seconds for each $\psi$. The peak position was determined by a Gaussian approximation.

\section{Delayed cracking analysis}

\subsection{Macroscopic observations}

Deep drawing tests have been performed on the 3 grades with Drawing Ratios (DR) varying between 1.52 and 2.00 at room temperature. For grade 1 , complementary tests have also been done at $85^{\circ} \mathrm{C}$ in order to analyze temperature effects on failure.

\subsubsection{Influence of drawing ratios and temperature on delayed cracking of grade 1 steel}

Just after deep drawing at room temperature of the grade 1, none of the cups exhibits failure. 24 hours later, the $\mathrm{DR}=2.00$ cup presented one crack located at $45^{\circ}$ from the rolling direction; later on, no new failure appear in that cup and no cracks have been observed for lower DR. The existing crack propagates down to the cup: its length increases from $1 \mathrm{~mm}$ (after $24 \mathrm{hrs}$ ) to $4 \mathrm{~mm}$ after one week. It did not evolve anymore, even after 3 years.

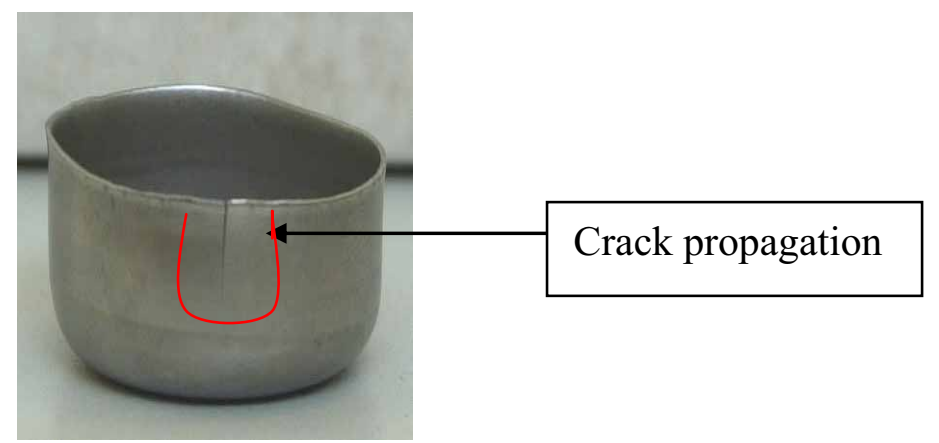

Fig. 2. Grade 1 cup deep-drawn at room temperature $(\mathrm{DR}=2.00)$.

When deep drawing is realized at $85^{\circ} \mathrm{C}$, no crack was observed whatever the drawing ratios. An increase of the temperature decreases the volume fraction of martensite formed during the deformation: the maximum volume fraction obtained after a tensile test is only $18 \%$ at $85^{\circ} \mathrm{C}$ and raises up to $40 \%$ at $20^{\circ} \mathrm{C}$ [9]. Therefore the material is less brittle. 


\subsubsection{Influence of pre-strain and chemical composition}

Figure 3 shows the 3 cups obtained with the 3 grades for a $D R=1.77$; cups were obtained by deep drawing at room temperature.

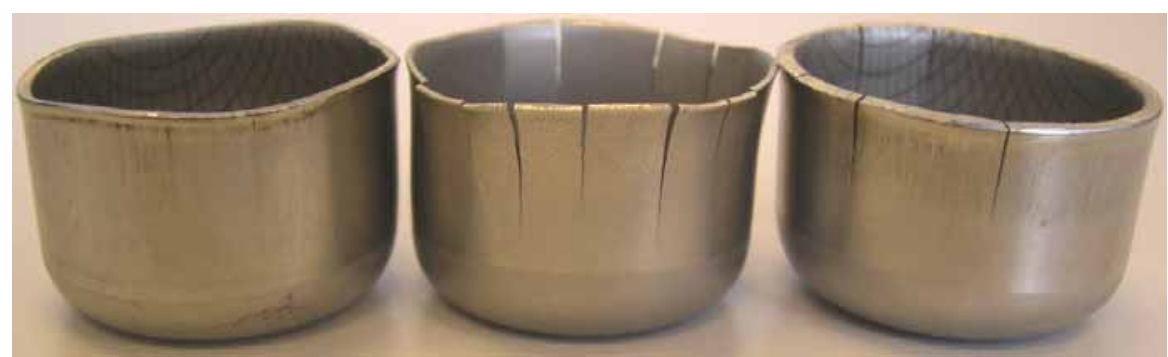

a)

b)

c)

Fig. 3. Delayed cracking in the 3 grades for $\mathrm{DR}=1.77$. a) grade 1. b) grade 3 (high carbon content). c) grade $1+$ skin-pass

On grade 2, several cracks have been observed several hours after deep drawing in cups with a DR higher than 1.77: 5 cracks for $\mathrm{DR}=1.77$ and 10 cracks for $\mathrm{DR}=2.00$. They propagated quite rapidly along the cup; their length reaches $9 \mathrm{~mm}$ after a few days, that corresponds to the half-length of the cup. They are located along the whole periphery of the cup, without with the initial sheet rolling direction.

The high carbon content grade is the more sensitive: it was the first to break after deep drawing and it occurs even for the lowest DR. Moreover, as it can be seen on figure 3c, the number of cracks is important (up to 15 cracks in a cup) and their mean length is $12 \mathrm{~mm}$. Carbon is known to stabilize the austenite phase in steel but Krauss [9] have shown the yield strength and the hardness of the martensite phase increase too with the carbon content. Therefore the heterogeneity of mechanical properties between the two phases increases.

\subsection{Stress analysis}

Stress analyses by XRD have been performed on the cups. Measurements have been made on the martensite phase, all along the cup height in the tangential direction. Previous studies [10] have shown that the martensite stress state increases with the drawing ratio and decreases with increasing temperature. Along the cup, it reaches a maximum value at mid-heigth of the cup. Moreover, measurements performed along the rolling direction, the transverse direction and at $45^{\circ}$ from the rolling direction gave the same values: there are few heterogeneities along the circumference. This is in accordance with previous observations: there is no precise location of cracks at the cup circumference. Let us compare now the 3 grades. The stress evolutions along the cup height are plotted figure 4.

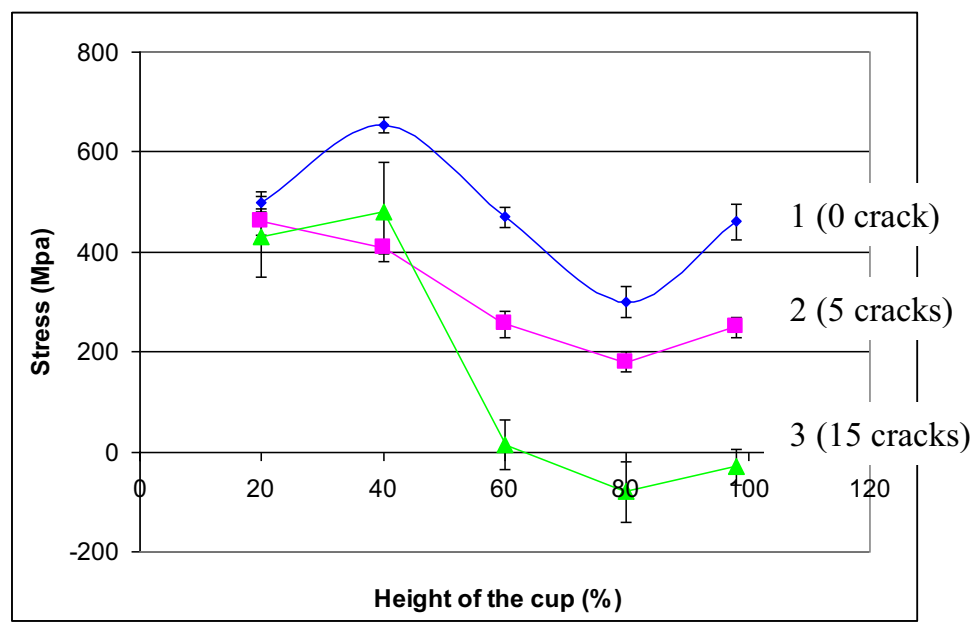

Fig. 4. Martensite tangential stress determined by XRD as a function of the cup height for the 3 grades (DR=1.77).

For the 3 grades, the martensite stress evolution goes through a maximum located near mid-height of the cups. The values are higher in the grade 1 than for the two others; the weaker one are obtained in the grade 3. 
The maximum stress is $655 \mathrm{MPa}$ in grade 1 and only $500 \mathrm{MPa}$ in grade 3 . The minimum value varies between $305 \mathrm{MPa}$ (for grade 1) and -80MPa (for grade 3): martensite is in compression.

When comparing grades 1 and 2, one can obtain the influence of a pre-strain as they have the same composition: it seems that the pre-strain leads to a decrease of the stress state as the curve has the same shape but is shifted towards lower stress values. The main difference between the three cups is that only the grade 1 steel has not experienced delayed cracking. This gives a clear relationship between the martensite stress state induced by the forming process and the occurrence of delayed cracking. We can then assume that residual stresses induced by the forming process are high enough to initiate and propagate a crack. This propagation allows stress relaxation in both phases, here in the martensite. It would be of interest to measure stress state just after deep drawing and before any crack has formed (less than 1 hour after forming!).

In grade 1, we had shown that the stress state was increasing with increasing DR. For grades 2 and 3 , the inverse trend has been observed: the bigger the DR is, the lower the stresses are. Once again, for these 2 grades, when DR increases, the number of cracks increases too and they are longer. This allows more stress relaxation in the cup whereas, in grade 1, no failure occurs and martensite keeps stressed.

\section{Conclusion}

We have measured the martensite stress state by XRD in relation to the delayed cracking phenomenon. If forming process do not lead to cracks formation in the cup, the martensite stress increases with increasing DR (that is with increasing strain). But if cracks appear after deep drawing, an increasing deformation leads to an bigger number of cracks which leads to a stress relaxation in the cup; therefore the martensite state decreases with increasing strain.

\section{References}

[1] H.C. Fiedler, Trans. ASM 47, 267(1955)

[2] G.H. Eichelman, T.C. Hull, Trans. Amer. Soc. Met. 45, 77 (1953)

[3] T. Angel, J. Iron and Steel Inst. 177, 165 (1954)

[4] C. B. Post, W.S. Eberly, Trans of the A.S.M 39, 868 (1946)

[5] R. Langeborg, Acta.Met. 12, 823 (1964)

[6] A.A. Lebedev, V. Kosarchuk, Int. Jour. Plas. 16, 749 (1999)

[7] G.B. Olson, M. Cohen, Met. Trans. 6A, 791 (1975)

[8] E. Macherauch, P. Muller, Rev. Appl. Phys. 13, 305 (1961)

[9] G. Krauss, Mat. Sci. Eng. A 273-276, 40 (1999)

[10] M.R. Berrahmoune, D. Bouscaud, K. Inal, S. Berveiller, E. Patoor, Mat. Sci. Eng. A 438-440, 262 (2006) 